\title{
Green logistics tools applied in selected companies in the Czech Republic: a survey
}

\author{
Jan Chocholáč ${ }^{1, *}$, Šárka Vančurová1, and Michal Míka ${ }^{1}$ \\ ${ }^{1}$ University of Pardubice, Faculty of Transport Engineering, Department of Transport Management, \\ Marketing and Logistics, Studentská 95, 53210 Pardubice 2, Czech Republic
}

\begin{abstract}
Research background: The issue of green logistics is a very current topic not only from a scientific point of view but also from the point of view of business practice. The pressure to reduce negative environmental, social and economic impacts presents new challenges and pressures for companies, which will become more important in the coming years. This manuscript deals with green logistics tools applied in selected companies in the Czech Republic. The manuscript strictly focuses on the view of companies on green logistics and its tools, as well as on barriers and drivers for the implementation of green logistics. The aim of the article is to identify the attitude of selected companies in the Czech Republic to green logistics, to analyse barriers and drivers in the implementation of green logistics and to analyse the applied activities of green logistics and the reasons for their application.

Purpose of the article: The main aim of the article is to identify the attitude of selected companies in the Czech Republic to green logistics and green logistics tools, to analyse barriers and drivers in the implementation of green logistics and to analyse the applied activities of green logistics and the reasons for their application. Finally, the results of this research are compared and discussed with the results of a study conducted in the Slovak Republic.

Methods: To conduct the research, we have used computer-assisted web interviewing with selected Czech companies' representatives.

Findings \& Value added: The results show that green logistics is very popular for companies. At the same time, barriers (most often financial) were identified, but also drivers and reasons for the implementation of green logistics tools. Comparing the results with the research conducted in the Slovak Republic, it can be stated that the results of both surveys were very similar, i.e. the location of the company in the Czech Republic or Slovakia does not affect the view of green logistics and its tools.
\end{abstract}

Keywords: green logistics; green logistics tools; drivers; barriers

JEL Classification: $R 41 ; M 11 ; O 32$

${ }^{*}$ Corresponding author: jan.chocholac@upce.cz 


\section{Introduction}

Logistics and transport are fields that are an integral part of every business. As people's needs grow, so do the demands on mobility and transport as such. With the help of new methods and processes, a company can greatly save operating costs, improve production capacity, but also gain a competitive advantage over other companies. Insufficient implementation of various measures can significantly increase its negative effects on the environment, which need to be reduced. The environmental aspect of this area is being studied by green logistics, which focuses on the impact of business processes on the environment and seeks to reduce the material and energy intensity of logistic activities. In recent years, their speeches have begun to increase interest in the way companies affect the environment and the extent to which companies' products negatively affect it. Therefore, the main responsibility of companies in relation to the environment and the support of their activities in this area. The implementation of green logistics has significant economic implications. Initial environmental protection requirements can impose costs and increased complexity on companies. However, the successful application of green logistics brings companies savings and innovation in the field of processes. At the same time, through green logistics, it is possible to build a relationship with customers, partners, and employees, which can help the company in differentiating products or gaining a competitive advantage.

$\mathrm{He}$ (2017) stated that with increasing global warming and environmental degradation, the green and low-carbon development mode is more and more widely accepted in the world. Logistic companies shouldn't only consider improving service quality and reducing operating costs but also should take a particular corporate social responsibility (hereinafter CSR) (Shi, 2020). Fahimnia et al. (2017) add that the growing environmental and social pressures exerted by governments, competitors, customers, society and caused by potential supply chain disruptions are driving corporations to implement sustainable and resilient practices. Seroka-Stolka et al. (2019) stated that green logistics is the main development trend of modern logistics, and it is an inherent condition and basic system of the development of the circular economy. Seroka-Stolka et al. (2019) stated, that green logistics is intended to assure that logistic processes are carried out correctly while minimizing their adverse impact on the natural environment. Zhao et al. (2020) add that the transport sector has extensive environmental, social, and economic impacts on society and thus is imperative for this sector to embrace the concept of sustainable development. Many green and sustainable logistic activities to reduce the negative effects were inspired by sustainable development (Abbasi et al., 2016). Mathieu (2019) stated that sustainable development meets the needs of present generations without compromising the ability of future generations to meet theirs. Seroka-Stolka et al. (2019) claim that green logistics, ecologistics and reverse logistics are closely interrelated and used in a circular economy. The relationship of all these three concepts is shown in Fig. 1.

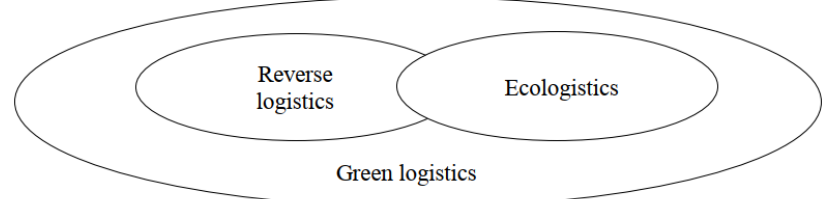

Figure 1. Relationship between reverse logistics, eco-logistics and green logistics.

Source: Seroka-Stolka et al. (2019)

Mejías et al. (2016) claim that the sustainability concept (Fig. 2) is supported by integrating environmental, social, and economic performance. 


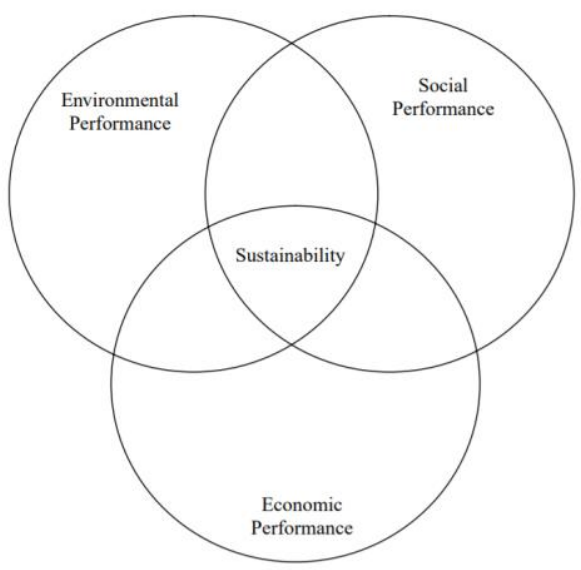

Figure 2. The triple bottom line concept.

Source: Carter et al. (2008)

At the intersection of social, environmental, and economic performance, there are activities that organizations can engage in which not only positively affect the natural environment and society but also result in long-term economic benefits and competitive advantage for the company (Carter et al., 2008). Solomon et al. (2019) add that the literature is increasingly focused on the perceived overlap between social, economic, and environmental performance and how an organization incorporates practices based on pressures, whether coercive, mimetic, or normative. Recent research aims to challenge this purported overlap and to demonstrate that social performance is a stand-alone indicator of successful environmental practice implementation (Rezaee et al., 2015). Solomon (2019) stated examples of environmental, economic, and social performance.

Table 1. Components of environmental, economic and social performance.

\begin{tabular}{lll}
\hline Environmental & Economic & Social \\
\hline $\mathrm{CO}_{2}$ emissions optimalization & Reduced fuel Consumption & Reduced noise \\
$\mathrm{GWP}$ impact optimalization & Optimized routes & Employee satisfaction \\
Toxicity/landfill amount reduction & Reduces environmental penalties & Enhanced safety \\
Waste amount reduction & Reduced delays; customer complains & Fair treatment \\
Certifications & Reduces fleet damage & Social acceptance \\
\hline
\end{tabular}

Source: Salomon et al. (2019)

Nawrocki et al. (2021) argue that in recent years, corporate involvement in CSR has become increasingly important and appreciated in the context of the ideas and assumptions regarding sustainable development. Sharma (2019) stated that CSR is the gateway for corporations to combine business with ethics, and it is needed to expand the focus of a corporation beyond merely its profit line. The author adds that there are similarities between CSR trends in the two distinct fields, such as emotion-oriented CSR programs and the use of media for corporate image building. Although the dimensions of CSR are under continuous deliberation among researchers and economists, businesses around the world are facing increasing pressures to be more socially vigilant and active contributors to their local and global communities (Sharma, 2019). This view is in line with the conclusion of Solomon's research. Solomon et al. (2019) stated that the results show that social performance positively impacts economic and environmental performance and that these results support the need for adding social performance as an individualized factor in the success measurement of sustainable practice implementation. ISO 26000:2010 provides 
guidelines on how businesses and organizations can operate in a socially responsible way, displaying an ethical and transparent behaviour that contributes to the health and welfare of society (ISO, 2016).

The aim of the article is to identify the attitude of selected companies in the Czech Republic to green logistics, to analyse barriers and drivers in the implementation of green logistics and to analyse the applied activities of green logistics and the reasons for their application. Finally, the results of this research are compared and discussed with the results of a study conducted in the Slovak Republic.

\section{Methods}

This research is designed as a cross-country comparative research (comparison of results in the Slovak Republic and the Czech Republic). Cross-country comparative research explicitly examines the differences or similarities between national (sub-)systems and policies (Burnham et al., 2008). In contrast to other types of social policy research, crosscountry comparison is a particularly diverse field that faces a distinctive set of challenges because of its focus on "large macro-social units" (Ragin, 1987). Cross-national comparisons therefore deal with entities of substantial complexity, both as wholes and in their parts, such as their ways of financing, approaches to service delivery, regulation, or the methods they use to assess the performance of providers (Cacace et al., 2013). The method of a cross-country comparative research was used, for example, in a study by Mejlgaard et al. (2019), Ciccia \& Javornik (2019), and Busse \& van Ginneken (2018).

The research methodology corresponds to Mala (2017) study. This study (Mala, 2017) was carried out in companies in the Slovak Republic in 2016. To conduct the research, we have used computer-assisted web interviewing with selected Czech companies' representatives due to the worsened epidemiological situation. The research in the Czech Republic was conducted from December 2020 to March 2021. The survey was divided into several stages: questionnaire preparation, question formulation, pilot survey, data collection, analysis of survey results and drawing conclusions. The first phase established the research objective and the areas to be targeted by the questionnaire. The aim of the research was to find out how green logistics is applied in selected companies in the Czech Republic and through which tools. The investigation covered the areas of perception of green logistics, motivation of companies to implement green logistics, government support and factors that may persuade or discourage companies to implement green logistics. Subsequently, a total of 17 survey questions were formulated. A pilot phase of the questionnaire was then conducted. The questionnaire was distributed to companies in the Czech Republic from various sectors and associations of companies.

\section{Results and Discussions}

A total of 63 enterprises from all over the Czech Republic participated in the survey, there are 9 micro enterprises, 9 small enterprises, 18 medium enterprises and 27 large enterprises. The largest number of enterprises was represented by enterprises operating on multinational markets $(66.7 \%$ of enterprises). The remaining enterprises are in national markets $(19.0 \%$ of enterprises), regional markets (12.7\% of enterprises) and local markets $(1.6 \%$ of enterprises). However, in the case of the application of green logistic tools, it is not only the size of the enterprise that matters, but also the focus of the enterprise plays a major role in meeting environmental objectives. Most companies (40 companies) operate in the transport and storage sector, 3 companies were in the wholesale and retail trade, motor vehicle repair and maintenance sector and 3 companies in the other activities sector. The tertiary sector was further represented by 1 company in the accommodation, food and beverage, and 
1 company in the information and communication activities sector. The secondary sector was followed in terms of the number of respondents by 8 companies from the manufacturing sector and 6 companies from the other activities sector. The primary sector, which is involved in the extraction and mining of raw materials, is represented by 1 company in other activities.

Another area of the questionnaire was the perception of green logistics by individual companies. Through this question it is possible to verify whether enterprises perceive green logistics as an individual activity or as a whole system of processes. As Fig. 3 declares, most enterprises perceive green logistics in their activities as the environmentally friendly processing of waste (29 responses). In the perception of green logistics, the second most important was the environmentally friendly way of transporting materials/goods (28 responses). A significant number of companies indicated a combination of different options, which suggests that companies perceive green logistics more as a system of individual processes. This assumption is confirmed by the third most frequent answer given by respondents, namely the environmentally responsible way of doing business (23 responses). Subsequently, companies indicated that they also perceive green logistics as environmental certification (21 responses), collecting information on energy consumption and $\mathrm{CO} 2$ emissions (15 responses) and working with customers to achieve environmental goals (13 responses). Respondents also indicated that they do not perceive green logistics in any way (two responses). Companies also added that they perceive green logistics as a company's environmental goals (one response), the implementation of information systems and the use of alternative drives (one response) or all of the above (one response).

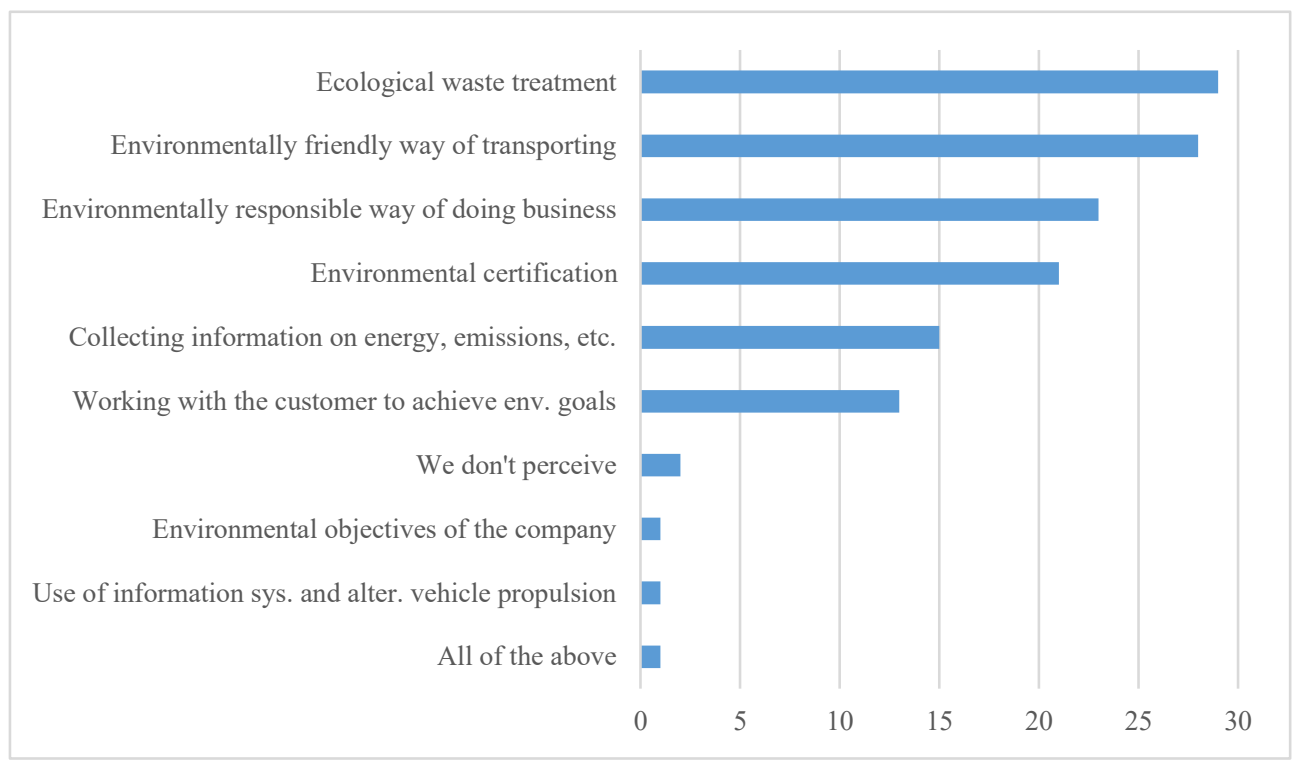

Figure 3. Respondents' perception of green logistics.

Source: authors

Large companies were very similar in their perception of green logistics, but the perception of micro, small and to some extent medium sized companies was mixed, indicating the variable awareness of companies.

Another area of the questionnaire was the application of green logistics tools in the company. Out of a total of 63 companies, 39 responded positively, i.e. that they apply green logistics tools. In terms of company characteristics, green logistics is more likely to be applied in multinationals and large companies. 55.5\% of the companies apply green 
logistics tools in micro companies, $44.4 \%$ in small companies and $50.0 \%$ in medium-sized companies. For large companies, $70.3 \%$ apply green logistics, which shows that these companies attach more importance to green logistics than smaller companies. In terms of sector, $52.5 \%$ of companies in transport and storage, $66.7 \%$ in wholesale trade, $87.5 \%$ in manufacturing, $80.0 \%$ in other activities and one company in accommodation, catering and hospitality. Furthermore, companies are most likely to apply green logistics mainly on the basis of their interest (30 responses). This shows that the strategy is important for the company. In some sectors it is not easy to implement green logistics tools. This is confirmed by the results for companies in the secondary sector, in which $90.9 \%$ of respondents indicated their own interest in implementing green logistics as essential. Then, in the next order, customer interest is significant for companies (20 responses). Employees are also an important incentive for companies (13 responses). Intermediate influences in the application of green logistics include the parent company (11 responses) and the government or other organisations (11 responses). The last interest mentioned was public pressure (1 response). It is noteworthy that there is no significant public pressure or interest in the application of green logistics and it does not influence companies in their decision making, although green logistics issues are a global issue. Instead, companies focus more on employees, customers and self-interest, which reflects the direction of the company.

The next area was already specific green logistics activities applied in companies. From the survey, it can be concluded that the activity most frequently applied by companies is waste separation and recycling (26 respondents). Related to this is the second most frequent activity of companies, namely the use of e-invoicing, which was identified by 25 respondents. 19 respondents reduce the volume of packaging material. Other frequently applied activities are optimising transport routes (24 respondents), efficient handling of transported material and efficient vehicle utilisation (18 respondents), and using transport that is less burdensome on the environment (13 respondents). It can be concluded that companies often apply activities that are more advantageous in terms of efficiency and investment. Furthermore, 18 respondents indicated that they apply efficient storage of materials and goods. Equally important for companies is environmental training of employees (17 respondents). Other applied activities include emission reduction as part of core corporate objectives, which was mentioned by 16 respondents, and environmental certification (14 responses). Surprisingly, companies do not make extensive use of alternative propulsion ( 8 responses) in transport and storage or renewable energy ( 7 responses). Other activities are working with partners and customers to achieve environmental goals (9 responses), selecting suppliers with regard to the company's environmental profile ( 7 responses) and buying local, green or reusable products (7 responses).

Financial resources are crucial in the process of applying green logistics tools and can influence the overall level in a company's decision-making. This question tells the company whether it is willing to invest a large amount of financial resources in green logistics and feels itself to be a 'green company' or rather implements activities that are less economically costly. For this question, the hypothesis that was stated for the question on the application of green logistics activities was confirmed. 59.0\% of the respondents answered that the financial aspect is important to them, but they also want to have a good impact on the external environment, so they try to invest financial resources efficiently when applying it. Another $20.5 \%$ of the respondents answered that their company aspires to be green and therefore they are able to invest a lot of financial resources in green logistics. This fact is of course also related to the size of the company. This policy was chosen by companies that are medium or large and have the ability to invest significant resources in green logistics. These companies have applied green logistics tools, such as the use of alternative drives in transport and storage or renewable sources, which are economically demanding. While 
another $20.5 \%$ of respondents, representing mainly small businesses, find their financial flows towards green logistics to be small because the size of the investment cost is important to them. These companies were most focused on waste policy activities in the application of green logistics tools.

Employee motivation is among the aspects that can help a company to implement green tools. Employees need to be motivated to do this so that green tools can be applied appropriately in the company. According to the questionnaire survey, enterprises have a positive attitude towards this issue and tend to motivate their employees in the field of green logistics. $38.5 \%$ of enterprises strongly support their employees and $48.0 \%$ of enterprises are of the opinion that they rather do. This result shows that enterprises perceive their employees as an important element in the application of green logistics and are willing to motivate them accordingly. The remaining $12.8 \%$ of enterprises are rather not supporting their employees in the application of green logistics tools. These are mainly enterprises that are not willing to devote a large amount of financial resources and probably do not motivate their employees for this reason. More than a third of the companies (37.5\%) said that image is definitely important to them and they attach great importance to green logistics in their marketing communication. The largest proportion (48.7\%) of companies believe that it rather does and may have a role in company presentation. The remaining $(12.0 \%)$ respondents are reticent and state that green logistics is rather not important for them in terms of image.

The application of green logistics tools over a five-year horizon focuses on the future direction of the company in the field of green logistics. Companies applying green logistics indicated that their future actions are most focused on the application of transport and transportation activities ( 25 responses). In addition, respondents consistently indicated that they will be looking at packaging processes (15 responses), material handling (15 responses) and reverse logistics (15 responses) in the coming period. This was followed by warehousing activities (14 responses), logistics communication (12 responses), purchasing ( 8 responses) and location of production and storage (3 responses). A small proportion of the companies surveyed indicated that they have no plans to expand into new activities (3 responses) and one company responded ambitiously that they want to achieve zero emissions within their company by 2050 .

Companies also indicated that they would be most persuaded to apply green logistics by more government support ( 24 responses). They would also be motivated by customer interest (17 responses). Costs are important for a lot of respondents, so it would be interesting for them if the cost of applying green logistics would be reduced (17 responses) and thus they would be more competitive (16 responses). Furthermore, companies perceive aspects such as company image (15 responses) and last but not least an increase in company profit (12 responses). One respondent stated that it would be important for them if green logistics were included more in the corporate vision.

From the perspective of companies applying green logistics, the main barriers are high investment costs (33 responses), high operating costs (18 responses) and uncertain return on investment (17 responses). Other barriers identified by companies included lack of interest from actors in the supply chain (13 responses), lack of customer interest ( 8 responses) and lack of resources ( 7 responses). At the same time, one respondent stated that they saw little government support as a barrier to the introduction of green logistics.

Companies applying green logistics tools are of the opinion that public support should be increased (35 responses). Other companies stated that support would not play a role in the implementation of green logistics in their companies. For companies that do not apply green logistics, 13 respondents said that public support for green logistics should be increased, 4 companies said that it would not play a role and 1 respondent said that they thought that the current support was adequate. One respondent also stated that they do not 
agree that additional public funds should be spent on supporting green logistics. This shows that companies overwhelmingly responded that they believe that current public support is insufficient and should be increased.

The results of the study processed in the selected companies in the Czech Republic are then compared with the results of the similar study prepared by Mala (2017). In the area of perception of green logistics, Slovak companies perceive the term green logistics as primarily the use of environmentally friendly packaging, followed by environmentally friendly transport, environmentally friendly waste treatment and environmentally friendly way of doing business. In this respect, the sample of Czech companies and Slovak companies perceive the value of green logistics similarly. They perceive green logistics mainly in the areas of waste policy, transportation and overall way of doing business. In the area of application of green logistics, Slovak companies mostly implement activities such as waste separation and recycling, use of electronic invoicing, followed by transport and packaging in individual activities. The difference compared to the sample of Czech companies is mainly visible in activities in transport and renewable energy. The Slovak companies favour activities in the mode of transport that are less burdensome on the environment, modification of vehicles to reduce consumption and the use of renewable energy sources. In contrast, selected Czech companies are more likely to apply activities in the area of employee training, environmental certification and emission reduction as part of basic corporate objectives. The shift towards green logistics presents both opportunities and barriers for companies. Compared to the Czech selected companies, Slovak companies strongly perceive cost reduction for enterprises as an opportunity and reason for applying green logistics. Mala (2017) adds that up to $80 \%$ of the companies would be convinced to apply green logistics mainly for economic reasons rather than environmental reasons, therefore, the companies cite the following as other reasons: increasing the name or image of the company, increasing competitiveness and other opportunities. Interestingly, companies further do not prioritize government support and rather consider factors that would help them with the marketing side, in order to improve the processes of the company. In this respect, they differ from the selected Czech companies, which cite greater government support as one of the key opportunities. The last area is barriers to the implementation of green logistics activities in the company. These are among the important factors that may discourage a company from implementing green logistics. Slovak companies consider high upfront investment costs, lack of financial resources, lack of state support and others as the biggest barriers. These barriers are very similar to those of the sample of Czech companies, except that Slovak companies ranked lack of knowledge in implementing green logistics among the important barriers. Slovak companies perceive green logistics similarly to the selected companies in the Czech Republic and apply a proportion of the same activities. Although they focus more on renewable energy or less environmentally burdensome transport modes, their attitude towards green logistics is similar. They perceive the opportunities and barriers for implementing green logistics similarly. Comparing the results of the analyses of both countries, the application is not influenced by a different geographical environment and the perception of the green logistics is very similar.

\section{Conclusions}

Logistics is one of the fields that are an essential part of every company. In addition to the positive effects, there are also negative ones associated with logistics. People are not indifferent to the future of our country and this increases the societal pressure on companies, increasing the demand to pay more attention to their environmental profiles in order to put less strain on the environment. However, the successful application of green 
logistics brings companies savings and process innovation. At the same time, green logistics can build relationships with stakeholders that can help a company differentiate its products or gain a competitive advantage. The aim of the article was to identify the attitude of selected companies in the Czech Republic to green logistics, to analyse barriers and drivers in the implementation of green logistics and to analyse the applied activities of green logistics and the reasons for their application. In conclusion, it can be stated that the application is not influenced by a different geographical environment and the perception of the green logistics is very similar in the Czech and Slovak Republic.

\section{Acknowledgements}

This paper is published within the solution of the scientific research project of the University of Pardubice no. SGS_2021_018. The authors are grateful for their support.

\section{References}

1. Abbasi, M., \& Nilsson, F. (2016). Developing environmentally sustainable logistics. Transportation Research Part D: Transport and Environment, 46, 273-283.

2. Burnham, P., Gilland, K., Grant, W., \& Layton-Henry, Z. (2008). Research methods in politics. Palgrave Macmillan.

3. Busse, R., \& van Ginneken, E. (2018). Cross-country comparative research - Lessons from advancing health system and policy research on the occasion of the European Observatory on Health Systems and Policies' 20th anniversary. Health Policy, 122(5), 453-456.

4. Cacace, M., Ettelt, S., Mays, N., \& Nolte, E. (2013). Assessing quality in cross-country comparisons of health systems and policies: Towards a set of generic quality criteria. Health Policy, 112(1-2), 156-162.

5. Carter, C. R., \& Rogers, D. S. (2008). A framework of sustainable supply chain management: moving toward new theory. International Journal of Physical Distribution \& Logistics Management, 38(5), 360-387.

6. Ciccia, R., \& Javornik, J. (2019). Methodological Challenges for Comparative Welfare State Research: Capturing Intra-Country Variation in Cross-National Analyses. Journal of Comparative Policy Analysis, 21(1), 1-8.

7. Fahimnia, B., Sarkis, J., Gunasekaran, A., \& Farahani, R. (2017). Decision models for sustainable supply chain design and management. Annals of Operations Research, 250(2), 277-278.

8. He, Z., Chen, P., Liu, H., \& Guo, Z. (2017). Performance measurement system and strategies for developing low-carbon logistics: A case study in China. Journal of Cleaner Production, 156, 395-405.

9. ISO (2016). Benefits in applying ISO 26000 - selected case studies as a result of the SR MENA project. https://www.iso.org/files/live/sites/isoorg/files/archive/pdf/en/srmena_factsheets.pdf

10. Mala, D. (2017). Zelena logistika a jej uplatnovanie $v$ praxi malych a strednich podnikov. Belianum.

11. Mejías, A. M., Paz, E., \& Pardo, J. E. (2016). Efficiency and sustainability through the best practices in the Logistics Social Responsibility framework. International Journal of Operations \& Production Management, 36(2), 164-199. 
12. Mejlgaard, N., Bloch, C., \& Madsen, E. B. (2019). Responsible research and innovation in Europe: A cross-country comparative analysis. Science and Public Policy, 46(2), 198-209.

13. Nawrocki, T. L., \& Szwajca, D. (2021). A Multidimensional Comparative Analysis of Involvement in CSR Activities of Energy Companies in the Context of Sustainable Development Challenges: Evidence from Poland. Energies, 14(15), 4592.

14. Ragin, C. (1987). The comparative method: moving beyond qualitative and quantative strategies. University of California Press.

15. Rezaee, A., Dehghanian, F., Fahimnia, B., \& Beamon, B. (2015). Green supply chain network design with stochastic demand and carbon price. Annals of Operations Research, 250(2), 463-485

16. Seroka-Stolka, O., \& Ociepa-Kubicka, A. (2019). Green logistics and circular economy. Transportation Research Procedia, 39, 471-479.

17. Sharma, E. (2019). A review of corporate social responsibility in developed and developing nations. Corporate Social Responsibility and Environmental Management, 26(4), 712-720.

18. Shi, Y., Zhou, Y., Ye, W., \& Zhao, Q. Q. (2020). A relative robust optimization for a vehicle routing problem with time-window and synchronized visits considering greenhouse gas emissions. Journal of Cleaner Production, 275, Article 124112.

19. Solomon, A., Ketikidis, P., \& Koh, S. C. L. (2019). Including social performance as a measure for resilient and green freight transportation. Transportation Research Part D: Transport and Environment, 69, 13-23.

20. Strale, M. (2019). Sustainable urban logistics: What are we talking about? Transportation Research Part A: Policy and Practice, 130, 745-751.

21. Zhao, X., Ke, Y., Zuo, J., Xiong, W., \& Wu, P. (2020). Evaluation of sustainable transport research in 2000-2019. Journal of Cleaner Production, 256, Article 120404. 